Jos Hornikx, ElizABETH DE

Groot, Ellen Timmermans,

Judy Mariëns en Jan Pieter

VERCKENS

\title{
Is het aanpassen van advertenties aan culturele waarden in West-Europa zinvol?
}

1. Internationale reclame: standaardisatie en adaptatie

Onder tekstschrijvers en -onderzoekers is het gemeengoed om te stellen dat een overtuigende tekst moet aansluiten bij de doelgroep om succesvol te kunnen zijn (zie Benoit \& Benoit, 2008). Rekening houden met kenmerken van de doelgroep zou de kans op succes voor een overtuigende tekst vergroten. Een van de ontvangerskenmerken die een rol van betekenis speelt in het overtuigingsproces is de culturele achtergrond van de doelgroep. Op basis van eerdere onderzoeken concluderen Hoeken, Hornikx en Hustinx (2009) in hun hoofdstuk over cultuur en het overtuigingsproces dat de culturele achtergrond van doelgroepen effect kan hebben op het overtuigingsproces, maar dat dit effect niet eenduidig is. De meest prominente lijn van onderzoek naar cultuur en overtuigingskracht wordt volgens Hoeken et al. (2009) gevormd door de studie van culturele waarden in reclame.

Binnen het onderzoeksveld van de internationale reclame is de aandacht voor culturele waarden in reclame vooral gerelateerd aan het vraagstuk over standaardisatie versus adaptatie. De centrale vraag is daarbij of het verstandiger is om reclame in verschillende landen uniform te houden (standaardisatie) of om reclame aan te passen aan de lokale voorkeuren,
Een prominente lijn van onderzoek naar cultuur en reclame wordt gevormd door experimenten waarin advertenties met cultureel aangepaste waardeappels worden vergeleken met advertenties met cultureel onaangepaste waardeappels. Uit een eerdere meta-analyse van bestaande experimenten bleek dat aangepaste advertenties overtuigender zijn en meer gewaardeerd worden dan onaangepaste advertenties, maar dat dit effect niet optrad voor West-Europese proefpersonen (Hornikx \& O'Keefe, 2009). Een oorzaak hiervoor ligt mogelijkerwijs in de gebruikte waardedimensies: in studies met Europese proefpersonen werden waardeappels nauwelijks aangepast aan individualisme - collectivisme, terwijl andere studies met deze waardedimensie juist aanpassingseffecten vonden. In een nieuwe serie experimenten werd daarom nagegaan of advertenties met een aangepast individualistisch waardeappel in West-Europese landen effectiever waren dan advertenties met een onaangepast collectivistisch waardeappel. Een meta-analyse van deze experimenten laat zien dat ook aanpassing aan individualisme - collectivisme geen voordeel oplevert in advertenties voor West-Europese proefpersonen. 
normen en waarden van die landen (adaptatie). De voordelen van standaardisatie van reclame zouden vooral economisch van aard zijn. Door overal dezelfde advertenties te gebruiken zouden er bijvoorbeeld kosten bespaard kunnen worden en is de kans op een uniform merkimago groter (De Pelsmacker, Geuens, \& Van den Berg, 2008; Fill, 2006; White, 2000). Aan de andere kant wijzen voorstanders van aanpassing op verschillen in attitudes, gewoonten en gedrag van consumenten uit verschillende culturen. Reclame die is afgestemd op deze verschillen zou effectiever moeten zijn dan gestandaardiseerde reclame. De Mooij (2005) stelt zelfs dat reclameadvertenties pas effectief zijn áls ze cultureel zijn aangepast. Het debat van voor- en tegenstanders van standaardisatie lijkt als voorlopige status quo het denkbeeld te hebben dat standaardisatie toegepast moet worden waar het mogelijk is en dat er daarnaast aangepast moet worden wanneer dat nodig is (Taylor, 2002; Taylor \& Johnson, 2002). Men zou kunnen stellen dat aanpassing nodig is, wanneer het vermoeden bestaat dat een lokaal aangepaste advertentie effectiever zou kunnen zijn voor een specifieke doelgroep dan het gestandaardiseerde origineel. Dit vermoeden is terug te voeren op inzichten uit sociaalcultureel onderzoek en de cross-culturele psychologie.

Het is inmiddels algemeen geaccepteerd dat de mens naast individuele kenmerken ook kenmerken heeft die cultuurbepaald zijn (zie Triandis \& Suh, 2002). Binnen een bepaalde cultuur delen mensen culturele gewoonten, waarden en normen die van generatie op generatie worden doorgegeven. Om culturen te beschrijven aan de hand van hun overeenkomsten en verschillen is de strategie van waardehiërarchieën het meest populair: het rangschikken van belangrijke en minder belangrijke waarden binnen een cultuur (Fiske, Kitayama, Markus, \& Nisbett, 1998). Met name Hofstede (1980, 2001) heeft empirisch aangetoond dat culturen gekenmerkt kunnen worden op basis van hun waardehiërarchieën. Culturen hechten in meer of mindere mate belang aan bepaalde waarden, zoals vrijheid, voor elkaar zorgen en creativiteit. In Hofstede's (1980, 2001) onderzoek bleken deze belangen te kunnen worden getypeerd aan de hand van vijf waardedimensies: individualisme - collectivisme, hoge - lage onzekerheidsvermijding, kleine - grote machtsafstand, masculiniteit - femininiteit en korte - langetermijnoriëntatie (Hofstede, 1980, 2001). Elke cultuur kreeg in Hofstede's onderzoek een score op elke dimensie. Zo bleek de Noord-Amerikaanse cultuur bij bijvoorbeeld de dimensie individualisme - collectivisme extreem hoog te scoren op individualisme. Dit betekent dat er in deze cultuur meer belang wordt gehecht aan individualistische waarden (vrijheid, zelfstandigheid) dan aan collectivistische waarden (bij een groep horen, voor elkaar zorgen). Een grootschalig, recenter onderzoek van House et al. (2004) in 62 landen bevestigt het belang van culturele dimensies en culturele waarden in het onderscheiden van nationale culturen.

In reclameadvertenties spelen deze culturele waarden een belangrijke rol, omdat waarden voor een groot deel bepalen of consumenten een product wel of niet aantrekkelijk vinden. Bij de promotie van producten of diensten ligt de nadruk doorgaans op de wenselijke kenmerken van die producten of diensten. Zo kan een auto worden aanbevolen aan de hand van het hoge aantal airbags of de fijne stoelen. De wenselijkheid van die kenmerken wordt afgewogen aan de hand van het belang dat consumenten hechten aan bepaalde waarden, in dit geval veiligheid (airbags) en comfort (stoelen). Iemand die veel waarde hecht aan veiligheid zal de aanwezigheid van airbags in een auto interessanter vinden dan de inbouw van fijne stoelen (zie ook Le Pair, Crijns, \& Hoeken, 2000). Het noemen van de airbags en aldus het benadrukken van veiligheid in een autoreclame vormt een waardeappel. De advertentie appelleert dan aan een waarde: veiligheid. Omdat culturen bepaalde waarden belangrijker 
vinden dan andere, zouden advertenties waarin wordt ingespeeld op waarden die belangrijk zijn in een cultuur overtuigender moeten zijn dan advertenties waarin wordt ingespeeld op waarden die onbelangrijk zijn in een cultuur. Advertenties met cultureel belangrijke waarden worden advertenties met cultureel aangepaste waardeappels genoemd en advertenties met cultureel onbelangrijke waarden worden advertenties met cultureel onaangepaste waardeappels genoemd.

\section{Onderzoek naar cultureel aangepaste waardeappels}

In de loop der jaren is een aantal studies uitgevoerd om te onderzoeken of cultureel aangepaste waardeappels in reclame effectiever zijn dan cultureel onaangepaste waardeappels. Een van de eerste studies op dit gebied is het onderzoek van Han en Shavitt (1994). NoordAmerikaanse en Koreaanse proefpersonen kregen in dat onderzoek advertenties voorgelegd die, op basis van Hofstede (1980), cultureel belangrijke waarden of cultureel onbelangrijke waarden bevatten. Daarbij werd verondersteld dat het individualistische appel voor de Noord-Amerikanen overtuigend zou moeten zijn en voor de Koreanen niet, terwijl het collectivistische appel juist voor de Koreanen overtuigend zou moeten zijn en voor de Noord-Amerikanen niet. Voor beide culturele groepen werd een aanpassingseffect gevonden: advertenties met cultureel aangepaste waardeappels bleken overtuigender dan advertenties met cultureel onaangepaste waardeappels. Voor de Noord-Amerikaanse proefpersonen, bijvoorbeeld, waren advertenties met een individualistisch waardeappel overtuigender dan met een collectivistisch waardeappel.

De resultaten van het onderzoek van Han en Shavitt (1994) ondersteunen het belang van aanpassing in internationale reclame ten faveure van standaardisatie. Het aanpassingseffect is in andere studies ook opgetreden (bijvoorbeeld Aaker, 2000), maar soms ook niet (bijvoorbeeld Aaker \& Williams, 1998). Le Pair et al. (2000) rapporteren over zes van dergelijke onderzoeken, waarvan vijf aantoonden dat aangepaste advertenties overtuigender waren en één aantoonde dat het onaangepaste appel overtuigender was. Le Pair et al. (2000) doen op basis van deze zes onderzoeken geen uitspraken over de mate waarin aanpassing overtuigender was dan geen aanpassing: was het een klein, gemiddeld of groot effect? Bovendien zijn er na de overzichtsstudie van Le Pair et al. (2000) een aantal nieuwe experimentele onderzoeken uitgevoerd waarin advertenties met een cultureel aangepast waardeappel zijn vergeleken met advertenties met een cultureel onaangepast waardeappel. Om die redenen hebben Hornikx en O'Keefe (2009) recentelijk een meta-analyse uitgevoerd naar dergelijke experimenten. Voor elke studie die werd gevonden berekenden zij een effectgrootte voor de afhankelijke variabelen overtuigingskracht (bijvoorbeeld attitude ten opzichte van het product of koopintentie) en/of de attitude ten opzichte van de advertentie. De studies leverden samen 67 effectgroottes op voor overtuigingskracht en 61 effectgroottes voor attitude ten opzichte van de advertentie. De meta-analyse liet zien dat advertenties met cultureel aangepaste waardeappels overtuigender zijn en meer gewaardeerd worden dan advertenties met cultureel onaangepaste waardeappels.

Ook deze meta-analyse lijkt daarmee het belang van aanpassing boven standaardisatie te onderstrepen. Deze conclusie blijkt echter te simpel. Hornikx en O'Keefe (2007, 2009) lieten namelijk ook zien dat het aanpassingseffect in sommige omstandigheden niet optreedt. Een van deze omstandigheden betreft Europeanen als doelgroep voor aangepaste en 
onaangepaste waardeappels in advertenties. Hornikx en O'Keefe $(2007,2009)$ vonden in de literatuur meer dan 20 vergelijkingen tussen cultureel aangepaste en cultureel onaangepaste waardeappels in reclameadvertenties die waren voorgelegd aan proefpersonen uit zeven verschillende West-Europese landen: België, Denemarken, Duitsland, Frankrijk Groot-Brittannië, Nederland en Spanje. Gemiddeld genomen was er geen aanpassingseffect op overtuigingskracht en op attitude ten opzichte van de advertentie voor deze West-Europeanen (Hornikx \& O'Keefe, 2007, 2009). Alleen in de vergelijking waarbij de waardeappels waren gemanipuleerd op masculiniteit - femininiteit werd er een aanpassingseffect gevonden, maar dit effect gold alleen voor de attitude ten opzichte van de advertentie.

\section{Geen aanpassingseffect voor West-Europeanen?}

Hornikx en O'Keefe (2009) gaan een aantal mogelijke verklaringen na die er wellicht voor hebben gezorgd dat het aanpassingseffect in hun gehele meta-analyse relatief klein is - en daarmee ook dat het aanpassingseffect voor West-Europeanen afwezig is. Ten eerste zouden onderzoekers wellicht onhandige keuzes gemaakt kunnen hebben in de cultureel belangrijke en cultureel onbelangrijke waarden in hun experimenten. In het onderzoek van Hofstede $(1980,2001)$ wordt een schaal gebruikt van 0 (cultureel onbelangrijke waarden) tot 100 (cultureel belangrijke waarden). Bij de experimenten in hun meta-analyse vinden Hornikx en O'Keefe dat voor de cultureel belangrijke waarden het gemiddelde belang van de waarden boven de 80 ligt. Met de keuzes van de gebruikte waarden is daarom niets mis. Ten tweede zouden onderzoekers wellicht die goed gekozen waarden niet treffend genoeg gemanipuleerd kunnen hebben in hun materiaal. Maar ook deze verklaring schrijven Hornikx en O'Keefe af: de manipulatie was in de regel gebaseerd op corpus-analytisch onderzoek en zodoende kon er geen sprake zijn van verkeerde manipulaties in de experimenten.

Een andere oorzaak voor het uitblijven van een aanpassingseffect bij West-Europese proefpersonen zouden de gebruikte waardedimensies kunnen zijn, zoals ook Hoeken et al. (2003) suggereren. Het aanpassingseffect werd in Hornikx en O'Keefe (2009) namelijk vooral gevonden voor studies waarin de waardeappels wel of niet aangepast waren aan de dimensie individualisme - collectivisme. Slechts één van die studies betrof een onderzoek met West-Europese proefpersonen (Diehl \& Terlutter, 2004) ${ }^{1}$. Het zou zo kunnen zijn, dat het aanpassingseffect juist voor individualisme - collectivisme optreedt. Deze suggestie vloeit voort uit voorgaand onderzoek dat aantoont dat waardevoorkeuren op cultureel en individueel niveau niet per definitie overeenkomen (Smith \& Schwartz, 1997).Cultureel belangrijke waarden worden dus niet altijd door individuen persoonlijk belangrijk gevonden. Fischer (2006) kon bijvoorbeeld wel congruentie tussen cultureel en individueel niveau laten zien voor waarden gerelateerd aan individualisme - collectivisme, maar die congruentie was voor andere waarden minder evident. Die andere waarden worden wellicht minder goed overgenomen door individuen in een cultuur dan waarden die met de relatie tussen het individu en de groep te maken hebben. Als gevolg daarvan zou aanpassing van een waardeappel aan bijvoorbeeld de culturele dimensie femininiteit - masculiniteit op individueel niveau nauwelijks of geen effect sorteren, maar aanpassing aan de culturele dimensie individualisme - collectivisme juist wel. 
Hornikx en O'Keefe (2009) suggereren dat er meer onderzoek nodig is naar het effect van aanpassing aan individualisme - collectivisme bij West-Europeanen. Als het uitblijven van een aanpassingseffect bij West-Europese proefpersonen inderdaad ligt aan de gebruikte waardedimensies, dan zou er wel een aanpassingseffect moeten optreden voor individualisme collectivisme. In deze bijdrage wordt gevolg gegeven aan deze suggestie. Er wordt een vergelijking gemaakt tussen advertenties met cultureel belangrijke, individualistische waarden en advertenties met cultureel onbelangrijke, collectivistische waarden voor West-Europeanen. De onderzoeksvragen die centraal staan, zijn de volgende:

$\begin{array}{ll}\text { Onderzoeksvraag } 1 & \begin{array}{l}\text { Zijn advertenties met een individualistisch appel in West-Europa } \\ \text { overtuigender dan advertenties met een collectivistisch appel? }\end{array}\end{array}$

Onderzoeksvraag 2 Worden advertenties met een individualistisch appel in WestEuropa meer gewaardeerd dan advertenties met een collectivistisch appel?

\section{Methode}

Er zijn zes experimenten opgezet in drie van de vier volgens Hofstede (2001) meest individualistische West-Europese landen: België (2 experimenten), Groot-Brittannië (1 experiment) en Nederland (3 experimenten). Dat betekent dat in deze landen de grootste verschillen zijn gevonden tussen het belang dat wordt gehecht aan individualistische en aan collectivistische waarden. Deze landen zijn daarom het meest geschikt voor onderzoek naar de vraag of het individualistische waardeappel in West-Europa overtuigender is dan het collectivistische appel.

In de experimenten is variatie nagestreefd in de geadverteerde producten (bijvoorbeeld een mobiele telefoon of een huurauto), in de opmaak van de advertenties, in de manipulatie van waarden in de tekst en in het beeld van de advertenties en in de selectie van items voor de afhankelijke variabelen.

Omdat een volledige uitleg van de methode van elk van de zes experimenten te veel ruimte in beslag zou nemen en de methode in alle experimenten vergelijkbaar was, worden twee experimenten volledig toegelicht: experiment 2 (cappuccinoapparaat) en experiment 6 (mobiele telefoon).Van alle experimenten worden wel de proefpersoonkenmerken en de betrouwbaarheid van de afhankelijke variabelen weergegeven. ${ }^{2}$

4.1 Materiaal. Er zijn advertenties ontwikkeld voor verschillende producten of diensten van niet-bestaande merken: autoverhuur, een cappuccinoapparaat, een laptop en een mobiele telefoon. Om het waardeappel zo duidelijk mogelijk tot uitdrukking te brengen, is het appel zowel gemanipuleerd in tekst als in beeld. Voor de manipulatie van het waardeappel is gebruik gemaakt van het overzicht dat Gregory, Munch en Peterson (2002) geven van de individuele waarden (gebaseerd op Schwartz, 1992) die passen bij individualisme en bij collectivisme op cultureel niveau. Zo was er bij het verbale, individualistische appel in de advertentie voor het cappuccinoapparaat (experiment 2) sprake van een "trots gevoel", van "van alles ondernemen" en van voornaamwoorden als "mijn", "ik" en "mezelf", terwijl er bij het collectivistisch appel sprake was van een "vredig gevoel”, van "mooie momenten delen" en 
van voornaamwoorden als “onze", "we", “ons”. Bij de advertentie voor de mobiele telefoon (experiment 6) bestond het verbale, individualistische appel uit "Parijs...de stad van mijn keuze", "gaan en staan waar ik wil" en "snel een foto...om na te genieten van mijn reis". In het collectivistische equivalent waren bovenstaande fragmenten vervangen door "Parijs... de stad van onze keuze", "samen plezier beleven" en "snel een foto...zo kunnen we later nagenieten".

Voor de manipulatie van het waardeappel in beeld werden in de advertentie van het cappuccinoapparaat in het geval van het individualistische appel afbeeldingen gebruikt van een man in een keuken en van één kopje cappuccino. Bij het collectivistische appel stond naast dezelfde man een vrouw afgebeeld en bevatte de advertentie een afbeelding van twee kopjes cappuccino. Het beeld in de advertentie van de mobiele telefoon liet een jongeman zien die een foto van zichzelf makte (individualistisch appel) of toonde een andere jongeman die een foto van zichzelf en vier andere personen maakte (collectivistisch appel).

Om de advertenties realistischer te maken bevatten de advertenties naast de tekst en het beeld met het waardeappel ook informatie over de kenmerken van het product of de dienst. In de advertentie voor het cappuccinoapparaat stond bijvoorbeeld "Empressa E300, volautomatisch, gemakkelijk te bedienen, snel en eenvoudig te reinigen" en in de advertentie voor de mobiele telefoon stond onder andere "optische zoom 4x, Bluetooth, multimediaspeler". Figuur 1 toont de twee versies van de advertentie voor het cappuccinoapparaat en figuur 2 de twee versies van de advertentie voor de mobiele telefoon.
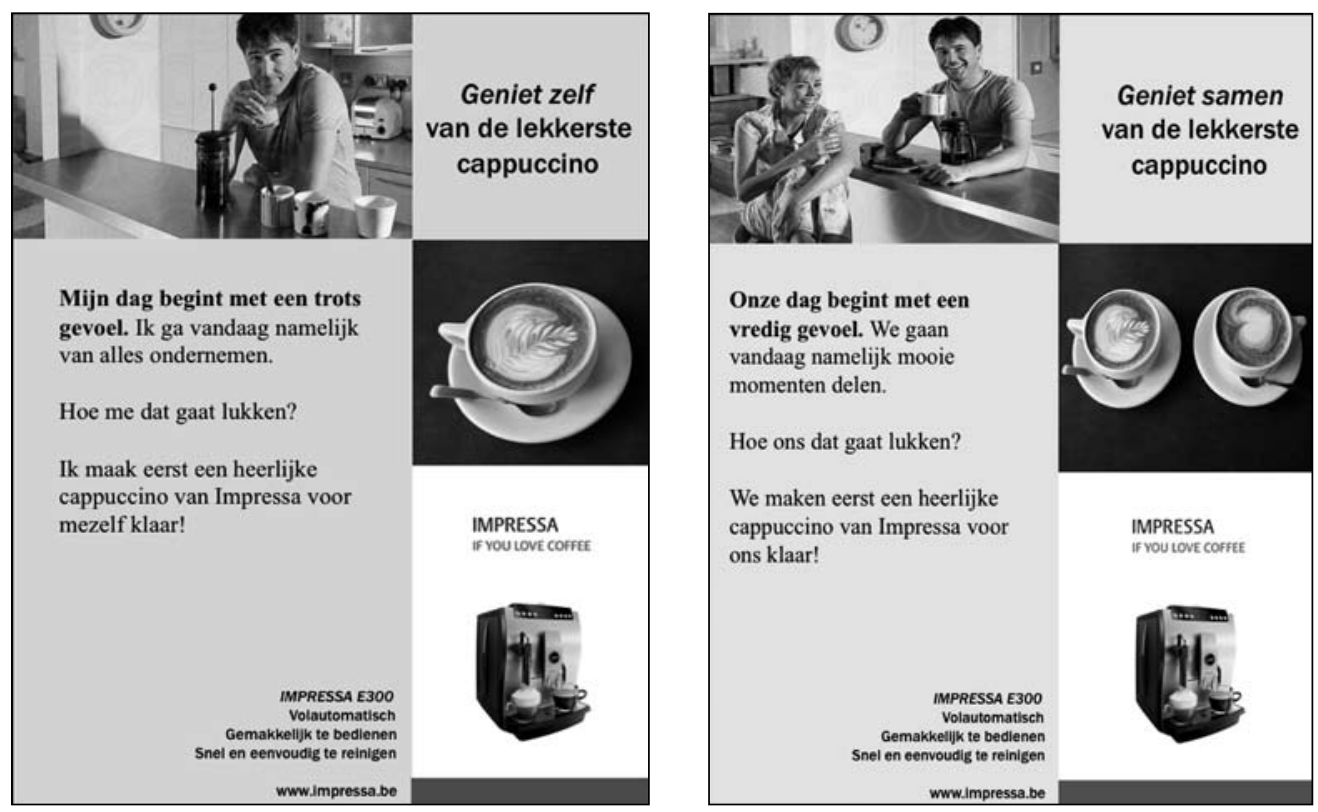

figuur 1 Advertenties voor experiment 2 (links: individualistisch; rechts: collectivistisch) 

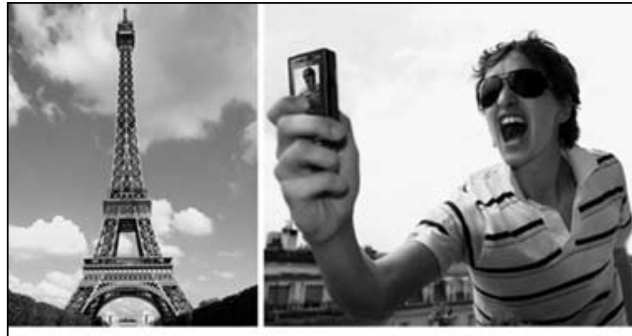

Parijs... De stad van mijn keuze

Gaan en staan woar ik wil

Snel een foto... om na te genieten van mijn reis

\section{FONEM XIr8}

folcholostol $13 \mathrm{MP}$

opliache $200 \mathrm{~cm} 4 \mathrm{~s}$

Filotocth

melimedospece

IFI scherm 15 mitom venom

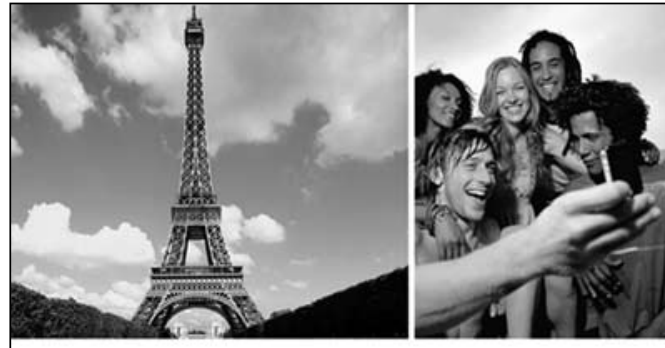

Parijs... De stad van onze keuze

Samen plezier beleven

Snel een foto... zo kunnen we later nagenieten
FONEM XIr8

fotoloestel $1.3 \mathrm{MP}$

optische zoom $4 x$

Bluetooth

multimediaspestor

Tif-scherm 16 miloen boum

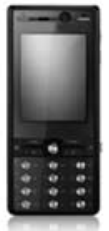

figuur $2 b$

figuur 2a

Advertenties voor experiment 6 (links: individualistisch; rechts: collectivistisch)

\subsection{Proefpersonen}

Zoals in het merendeel van de onderzoeken naar waardeappels in reclame (zie Hornikx \& O'Keefe, 2009), bestonden de groepen proefpersonen ook hier grotendeels uit studenten. In experiment 1 over autoverhuur was $57 \%$ van de proefpersonen student. Tabel 1 geeft een overzicht van het aantal proefpersonen per experiment, de gemiddelde leeftijd (en range), het percentage vrouwen en het opleidingsniveau. In totaal waren er 574 proefpersonen betrokken bij de zes experimenten.

Tabel 1: Proefpersoonkenmerken in de zes experimenten $(B E=$ België, $G B=$ Groot-Brittannië, $N L=N e d e r l a n d, W O=$ wetenschappelijk onderwijs)

\begin{tabular}{llllll}
\hline experiment & land & $n$ & leeftijd $(M$, range $)$ & $\%$ vrouwen & opleiding \\
\hline 1. autoverhuur & NL & 129 & $32.3,17-68$ & 56.6 & middelbaar - WO \\
2. cappuccino & BE & 127 & $21.6,17-29$ & 48.8 & WO \\
3. laptop & NL & 106 & $20.8,17-26$ & 45.3 & WO \\
4. mobiele telefoon & GB & 105 & $20.7,18-27$ & 53.3 & WO \\
5. mobiele telefoon & NL & 50 & $20.4,18-26$ & 72.0 & WO \\
6. mobiele telefoon & BE & 57 & $19.6,18-22$ & 63.2 & WO \\
\hline
\end{tabular}




\subsection{Instrumentatie}

In de instructies van elk experiment was telkens aangegeven dat er een nieuwe advertentie voor een product of dienst getest werd alvorens die mogelijk gebruikt ging worden. In elk experiment werd overtuigingskracht (onderzoeksvraag 1) gemeten op basis van de afhankelijke variabelen attitude ten opzichte van het product en koopintentie, en soms ook op basis van merkattitude. Daarnaast werd telkens de attitude ten opzichte van de advertentie (onderzoeksvraag 2) gemeten. Er is gestreefd naar variatie tussen de experimenten in de items die in het instrument voor elke variabele zijn meegenomen. Tabel 2 geeft een overzicht van de afhankelijke variabelen per experiment en de betrouwbaarheid van de items per variabele.

Tabel 2: Betrouwbaarheid $(\alpha)$ van de vier afhankelijke variabelen per experiment

\begin{tabular}{lllll}
\hline & $\mathrm{A}_{\text {product }}$ & $\mathrm{A}_{\text {merk }}$ & koopintentie & $\mathrm{A}_{\text {advertentie }}$ \\
\hline studie 1 & .80 & .74 & .79 & .84 \\
studie 2 & .74 & .77 & .70 & .76 \\
studie 3 & .89 & - & .79 & .82 \\
studie 4 & .79 & - & .76 & .72 \\
studie 5 & .72 & - & .83 & .87 \\
studie 6 & .80 & - & .83 & .85 \\
\hline
\end{tabular}

In experiment 2 met de advertentie van het cappuccinoapparaat werd de attitude ten opzichte van het product gemeten door vijf 7-punts semantische differentialen (bijvoorbeeld 'onaantrekkelijk - aantrekkelijk', 'goed - slecht', 'niet interessant - interessant'). De attitude ten opzichte van het merk werd gemeten door drie 7-punts semantische differentialen ('onbetrouwbaar - betrouwbaar', 'ondeskundig - deskundig', 'goed - slecht'). De koopintentie werd gemeten door drie 7-punts likertschalen (bijvoorbeeld "Ik overweeg dit cappuccinoapparaat aan te schaffen"). De attitude ten opzichte van de advertentie werd gemeten aan de hand van vijf 7-punts semantische differentialen (bijvoorbeeld 'mooi - lelijk', 'onopvallend - opvallend', 'aangenaam - vervelend').

$\mathrm{Na}$ de items die betrekking hadden op de afhankelijke variabelen werd telkens gevraagd welke boodschap de proefpersoon had herkend in de advertentie. In sommige experimenten werden twee opties gegeven (het appel van de beoordeelde advertentie en het appel van de advertentie die de proefpersoon niet te zien had gekregen). In experiment 6 naar de mobiele telefoon, bijvoorbeeld, moest de keuze gemakt worden tussen 'individuele ontplooiing' (individualistisch) en 'groepsgevoel' (collectivistisch). In andere experimenten werden deze twee opties aangevuld met twee andere boodschappen. In het onderzoek met het cappuccinoapparaat waren de opties 'aandacht voor het individu' (individualistisch), 'deel uitmaken van een groep' (collectivistisch), 'plezier' en 'bescheidenheid'. De proefpersonen bleken de juiste boodschap te herkennen in de advertenties van experiment $2\left(\chi^{2}(3)=25.64\right.$, $p<.001)$, in de advertenties van experiment $6\left(\chi^{2}(1)=30.02, p<.001\right)$ en in de advertenties van de andere experimenten $(p$ 's $<.001)$. 
Om inzicht te verkrijgen in de mate van individualisme - collectivisme bij de individuele proefpersonen werd een verkorte schaal van Singelis (1994) opgenomen. Waar nodig, werd het Engelstalige origineel vertaald in het Nederlands of het Vlaams. Bij experiment 2 met het cappuccinoapparaat werden acht items meegenomen voor individualisme (bijvoorbeeld "Ik vind het fijn om op verschillende manieren uniek en anders te zijn dan anderen") en acht items voor collectivisme (bijvoorbeeld "Het is belangrijk voor mij om de harmonie te behouden binnen mijn groep"). De proefpersonen gaven aan meer belang te hechten aan individualistische waarden dan aan collectivistische waarden $(t(126)=8.98$, $p<.001)$. Bij experiment 6 met de mobiele telefoon werden telkens vijf items meegenomen. Ook in dit experiment gaven de proefpersonen aan meer belang te hechten aan individualistische waarden dan aan collectivistische waarden $(t(56)=5.82, p<.001)$. In twee andere experimenten werd ook meer belang gehecht an individualistische waarden $(p$ 's $<.001$; experimenten 1 en 3), in één geval was er geen significant verschil (experiment 5) en in een ander geval werd er meer belang gehecht aan collectivistische waarden (experiment 4). Ter afsluiting van de vragenlijst werden de leeftijd, het geslacht, de opleiding en nationaliteit van de proefpersonen gevraagd.

4.4 Ontwerp. In elk experiment was er sprake van een tussenproefpersoonontwerp: proefpersonen kregen of een advertentie te zien met een individualistisch appel of een advertentie met een collectivistisch appel. In elk experiment was de verdeling van het aantal proefpersonen per versie ongeveer gelijk.

4.5 Procedure en statistische toetsing. De boekjes met de instructie, advertentie en vragenlijst werden aan mogelijke proefpersonen individueel, in kleine of in grotere groepen uitgereikt. In de meeste experimenten werden proefpersonen gezocht in collegezalen en op andere plaatsen op universiteitsterreinen. Proefpersonen kregen geen beloning voor hun medewerking. Er zijn geen storende factoren opgetreden.

In elk experiment is het effect van een cultureel aangepast en een cultureel onaangepast waardeappel vergeleken. Met een ANOVA is er voor elk experiment getoetst of het resultaat van de vergelijking significant was. Er is daarnaast een meta-analyse uitgevoerd om de resultaten van de experimenten samen te kunnen nemen. ${ }^{3}$ Omdat de items van de afhankelijke variabelen variëren over de verschillende experimenten, ligt een gelijktijdige analyse van alle data samen niet voor de hand, maar een meta-analyse van deze experimenten wel (zie Jackson, 1991).Voor elke vergelijking is de effectmaat $r$ berekend voor elke afhankelijke variabele - deze effectmaat is bij meta-analyses gebruikelijk. Bij overtuigingskracht zijn effectgroottes berekend voor elk van de twee of drie maten (attitude ten opzichte van het product, merkattitude, koopintentie), waarna er een gemiddelde is berekend voor overtuigingskracht via een $r$-z-r transformatie. Dat gemiddelde is gebruikt in de analyse. De uiteindelijke set van effectgroottes is via de random-effects procedure van Borenstein en Rothstein (2005) geanalyseerd.

\section{Resultaten}

Voor experiment 2 met de advertentie voor het cappuccinoapparaat werd een trend voor een hoofdeffect van appel gevonden op overtuigingskracht $(F(3,122)=2.63$, $p=.05)$ en 
een hoofdeffect van appel op de attitude ten opzichte van de advertentie $(F(1,125)=5.29$, $\left.p<.05, \mathrm{n}^{2}=.04\right)$. De Belgische proefpersonen vonden de advertentie met het individualistische appel overtuigender en waardeerden deze advertentie ook meer dan de advertentie met het collectivistische appel.Voor experiment 6 met de advertentie voor de mobiele telefoon werd een hoofdeffect van appel gevonden op overtuigingskracht $(F(2,54)=5.14, p<.001$, $\left.\mathrm{n}^{2}=.16\right)$, maar geen hoofdeffect op de attitude ten opzichte van de advertentie $(F(1,55)=$ $1.83, p=.18)$. Opvallend genoeg vonden de Belgische proefpersonen de advertentie met het collectivistische appel hier overtuigender dan de advertentie met het individualistische appel. Tabel 3 geeft de resultaten van het aanpassingseffect voor alle experimenten.

Tabel 3: Toets van het aanpassingseffect voor alle experimenten en berekende effectgrootte (COL = collectivistisch appel; IND = individualistisch appel)

\begin{tabular}{lll}
\hline experiment & overtuigingskracht & A $_{\text {advertentie }}$ \\
\hline 1. autoverhuur & IND $=\mathrm{COL}$ & IND $=\mathrm{COL}$ \\
& $F(3,125)=1.28, p=.29$ & $F(1,127)=2.54, p=.11$ \\
& $r=-.116$ & $r=-.139$ \\
2. cappuccino & IND $>\mathrm{COL}$ & IND $>\mathrm{COL}$ \\
& $F(3,122)=2.63, p=.05$ & $F(1,125)=5.29, p<.05, \mathrm{n}^{2}=.04$ \\
& $r=.194$ & $r=.200$ \\
3. laptop & IND $=\mathrm{COL}$ & IND $=\mathrm{COL}$ \\
& $F(3,102)<1$ & $F(1,104)=2.58, p=.11$ \\
& $r=.068$ & $r=.154$ \\
4. mobiele telefoon & IND $=\mathrm{COL}$ & IND $=\mathrm{COL}$ \\
& $F(3,101)<1$ & $F(1,103)<1$ \\
& $r=-.116$ & $r=-.139$ \\
5. mobiele telefoon & IND $=\mathrm{COL}$ & IND $=\mathrm{COL}$ \\
& $F(2,47)<1$ & $F(1,48)<1$ \\
& $r=.058$ & $r=.029$ \\
& $\mathrm{COL}>\mathrm{IND}$ & $\mathrm{IND}=\mathrm{COL}$ \\
6. mobiele telefoon & $F(2,54)=5.14, \mathrm{p}<.001, \mathrm{n}^{2}=.16$ & $F(1,55)=1.83, p=.18$ \\
& $r=-.263$ & $r=-.176$ \\
\hline
\end{tabular}

Variabiliteit in resultaten van soortgelijke onderzoeken, zoals tabel 3 laat zien, is op zich niet ongewoon (zie Hornikx \& O'Keefe, 2009). Omdat elk experiment antwoord geeft op dezelfde vraag, zijn de data in een meta-analyse samengenomen. In tabel 3 staan ook de berekende effectgroottes die zijn gevonden voor elke vergelijking. Een positief effect geeft aan dat het cultureel aangepaste waardeappel effectiever is dan het cultureel onaangepaste waardeappel en het getal drukt de grootte van dit effect uit. Een meta-analyse toetst of het gewogen gemiddelde van deze effectgroottes ook significant afwijkt van 0 (wanneer er geen aanpassingseffect is opgetreden). De huidige meta-analyse laat zien dat er geen significant effect van aanpassing is op overtuigingskracht $(k=6, r=-.022, p=.74$; meta-analytische power $=.38$ berekend aan de hand van Hedges $\&$ Pigott, 2001) of op attitude ten opzichte van de advertentie $(k=6, r=-.006, p=.93$, power $=.38)$. De onderzoeksvragen moeten daarom negatief worden beantwoord: advertenties met een individualistisch appel in WestEuropa bleken niet overtuigender en niet hoger gewaardeerd dan advertenties met een collectivistisch appel. 
6. Conclusie en discussie

In het debat tussen voor- en tegenstanders van standaardisatie en adaptatie in internationale reclame leek het pleit beslecht voor de voorstanders van adaptatie: de meta-analyse van Hornikx en O'Keefe (2009) toonde immers aan dat cultureel aangepaste advertenties overtuigender waren en meer gewaardeerd werden dan cultureel onaangepaste advertenties. De onderzoekers lieten echter ook zien dat achter deze algemene conclusie nog een nuancering schuilging: voor West-Europese proefpersonen trad het aanpassingseffect niet op. Omdat de waardeappels in deze West-Europese studies op één studie na niet waren aangepast aan de dimensie individualisme - collectivisme (waarvoor juist grote aanpassingseffecten werden gevonden), richtte het huidige onderzoek zich op deze dimensie. In zes experimenten werd bij West-Europese proefpersonen het effect van een aangepast individualistisch appel vergeleken met het effect van een onaangepast collectivistische appel. Het bleek dat aanpassing effectiever (experiment 2) of minder effectief (experiment 6) kan zijn dan geen aanpassing, maar bovenal dat - bij het samennemen van de experimenten in een meta-analyse - er in het algemeen geen aanpassingseffect optreedt. De aangepaste individualistische advertenties waren even overtuigend en werden even hoog gewaardeerd als de onaangepaste collectivistische advertenties.

Het resultaat van het huidige onderzoek is gebaseerd op zes experimenten met variatie in producten en diensten, in meetinstrumenten en in manipulatie van waardeappels. Om de kans op een aanpassingseffect te maximaliseren vond de manipulatie van waardeappels plaats in tekst én beeld en waren de proefpersonen afkomstig uit drie van de vier meest individualistische West-Europese culturen (België, Groot-Brittannië en Nederland). Proefpersonen herkenden de manipulatie van het appel in de advertenties en in meer dan de helft van de experimenten bleken proefpersonen bij de individuele meting van de mate van individualisme en collectivisme meer belang te hechten aan individualistische waarden dan aan collectivistische waarden. Door de bevinding dat het aanpassingseffect onder deze gunstige condities over het algemeen toch niet optreedt, kunnen er vraagtekens worden gezet bij de effectiviteit van cultureel aangepaste waardeappels voor West-Europeanen. Hoewel aanpassing aan individualistische waarden effectief kan zijn in Westerse culturen zoals de NoordAmerikaanse (bijv. Han \& Shavitt, 1994;), lijkt het op basis van het huidige onderzoek onwaarschijnlijk dat aanpassing van waardeappels aan individualisme voor West-Europeanen leidt tot meer overtuigende advertenties. Vanwege de matige power van deze meta-analyse is een definitieve conclusie echter voorbarig: op basis van deze zes experimenten is het te vroeg om te concluderen dat er in de populatie helemaal geen effect bestaat voor aanpassing aan individualisme - collectivisme. Wanneer de resultaten van de huidige experimenten worden gevoegd bij de resultaten van bestaande, vergelijkbare experimenten onder WestEuropese proefpersonen (zie Hornikx \& O'Keefe, 2009), dan is niettemin de enige conclusie dat aanpassing aan culturele waarden in West-Europa in het algemeen niet effectiever is dan geen aanpassing (voor overtuigingskracht: $k=28, r=.018, p=.529$, power $=.94$; voor attitude ten opzichte van de advertentie: $k=33, r=.035, p=.226$, power $=.97$ ). Hier en daar wordt er wel een aanpassingseffect gevonden bij West-Europese proefpersonen, zoals in experiment 2 of in de set van studies naar masculiniteit - femininiteit (Hornikx \& O'Keefe, 2009), maar de uitgevoerde experimenten samen laten zien dat er in de populatie geen effect aanwezig is. Aldus lijken de resultaten van de meta-analyses tot op zekere hoogte het 
idee te ondersteunen dat standaardisatie van reclame mogelijk is (De Pelsmacker et al, 2008). Binnen West-Europa zorgt het aanpassen aan culturele waarden blijkbaar niet voor effectievere reclame, wat impliceert dat aanpassing in deze regio onnodig extra kosten voor marketeers zou opleveren.

Een belangrijke vervolgvraag is waarom West-Europeanen niet gevoelig zouden zijn voor waardeappels in advertenties. Een mogelijk antwoord zit in de processen van globalisatie die belangrijke culturele waarden minder saillant maken (Craig \& Douglas, 2006; Shavitt, Lee, \& Johnson, 2008). Juist in West-Europa, waar inwoners relatief gemakkelijk in aanraking komen met waardeappels die zijn gerelateerd aan verschillende waardedimensies, is er wellicht een nivellering opgetreden tussen de verschillende belangen die worden gehecht aan diverse waarden (Hornikx \& O’Keefe, 2009). Zoals Hornikx en O’Keefe (2009) opmerken, zou deze verklaring getoetst kunnen worden door het aanpassingseffect in de loop van de tijd te bestuderen.Vooralsnog is de tijdspanne helaas te kort, want de vroegste studie dateert van 1994 (Han \& Shavitt, 1994). Kortom, globalisatie zou een verklaring kunnen zijn voor de ongevoeligheid van West-Europeanen voor waardeappels in advertenties, maar erg overtuigend is die verklaring nog niet.

De vraag waarom West-Europeanen niet zo gevoelig zouden zijn voor soorten waardeappels in advertenties kan wellicht beantwoord worden door te kijken naar het proces dat ontvangers waarschijnlijk doorlopen bij het beoordelen van waardeappels. Dat proces zou uit drie (onbewuste) stappen kunnen bestaan. In de eerste plaats moet de ontvanger het waardeappel herkennen. Met andere woorden, de ontvanger moet uit een afbeelding en/of een tekst een bepaalde waarde kunnen herleiden. In de tweede plaats moet die herkenning bij de ontvanger het belang dat hij of zij hecht aan de waarde activeren. In de derde en laatste plaats zou er dan een vergelijking moeten plaatsvinden tussen het getoonde waardeappel en het persoonlijke belang dat wordt gehecht aan die waarde. Als deze vergelijking positief uitvalt, zou het waardeappel overtuigender gevonden moeten worden dan als deze vergelijking negatief uitvalt. Bij de eerste fase lijkt er in deze huidige experimenten niets vreemds aan de hand met de proefpersonen: zij herkennen namelijk de waardeappels in de advertenties. Bij de tweede fase zou er mogelijkerwijs iets mis kunnen zijn gegaan. Het zou zo kunnen zijn dat de West-Europese ontvangers - om welke reden dan ook - zich niet afvragen wat het belang is dat ze zelf hechten aan de getoonde waarde. In de experimenten is er pas ná de oordelen over het product en de advertentie gevraagd naar het persoonlijke belang dat proefpersonen hechten aan individualistische en collectivistische waarden. Het is dus niet zeker of de herkenning van het waardeappel bij de ontvanger het belang dat hij of zij hecht aan de waarde heeft geactiveerd. Daarom zou vervolgonderzoek kunnen ingaan op de vraag in hoeverre West-Europeanen de eigen, individuele waarden activeren direct na blootstelling aan stimuli waarin waarden zijn gemanipuleerd, zoals advertenties of verhalen (zie Gardner, Gabriel \& Lee, 1999). Door zo'n vraag te beantwoorden wordt er hopelijk meer inzicht verkregen in de mechanismen van het effect van culturele aanpassing van waardeappels - een effect dat bij West-Europeanen voorlopig niet lijkt op te treden. 


\section{Noten}

1 De waardedimensie individualisme - collectivisme is waarschijnlijk niet zo vaak onderzocht, omdat onderzoekers graag twee culturele groepen vergelijken die volgens de dimensies van Hofstede $(1980,2001)$ duidelijk van elkaar verschillen. Binnen Europa zijn er op individualisme - collectivisme geen grote verschillen tussen landen, maar bijvoorbeeld wel op onzekerheidsvermijding (zie bijvoorbeeld Hoeken et al., 2007).

2 Het materiaal en de vragenlijst van elk experiment zijn op navraag beschikbaar bij de eerste auteur. De experimenten die met (5) en (6) worden aangegeven zijn de enige twee die gebruik maken van hetzelfde materiaal en dezelfde vragenlijst.

3 De auteurs zijn dank verschuldigd aan Daniel J. O'Keefe (Northwestern University, USA) voor zijn hulp bij deze analyse.

\section{Bibliografie}

Aaker, J.L. (2000). Accessibility or diagnosticity? Disentangling the influence of culture on persuasion processes and attitudes. Journal of Consumer Research, 26, 340-357.

Aaker, J.L., \& Williams, P. (1998). Empathy versus pride: The influence of emotional appeals across cultures. Journal of Consumer Research, 25, 241-261.

Benoit, W., \& Benoit, P. (2008). Persuasive messages: The process of influence. Malden, MA: Blackwell.

Borenstein, M., \& Rothstein, H. (2005). Comprehensive meta-analysis (Version 2.2.023). Englewood, NJ: Biostat.

Craig, C.S., \& Douglas, S.P. (2006). Beyond national culture: Implications of cultural dynamics for consumer research. International Marketing Review, 23, 322-342.

Diehl, S., \& Terlutter, R. (2004). Comparing the effects of individualistic versus collectivistic advertising on Germans and Chinese. In P. Neijens, C. Hess, B. van den Putte, \& E. Smit (Red.), Content and media factors in advertising (pp. 62-47). Amsterdam: Het Spinhuis.

Fill, C. (2006). Marketing communications: Engagement, strategies and practice (4e ed.). Harlow: Prentice Hall.

Fischer, R. (2006). Congruence and functions of personal and cultural values: Do my values reflect my culture's values? Personality and Social Psychology Bulletin, 32, 1419-1431.

Fiske, A.P., Kitayama, S., Markus, H.R., \& Nisbett, R.E. (1998). The cultural matrix of social psychology. In D.T. Gilbert, S.T. Fiske, \& G. Lindzey (Red.), The handbook of social psychology:Vol. 2 (4e ed., pp. 915-981). Boston: McGraw-Hill.

Gardner, W.L., Gabriel, S., \& Lee, A.Y. (1999). "I” value freedom, but “we” value relationships: Self-construal priming mirrors cultural differences in judgment. Psychological Science, 10, 321-326.

Gregory, G.D., Munch, J.M., \& Peterson, M. (2002). Attitude functions in consumer research: Comparing value-attitude relations in individualist and collectivist cultures. Journal of Business Research, 55, 933-942.

Han, S.-P., \& Shavitt, S. (1994). Persuasion and culture: Advertising appeals in individualistic and collectivistic societies. Journal of Experimental Social Psychology, 30, 326-350.

Hedges, L.V., \& Pigott, T.D. (2001). The power of statistical tests in meta-analysis. Psychological Methods, 6, 203-217.

Hoeken, H., Brandt, C. van den, Crijns, R., Domínguez, N., Hendriks, B., Planken, B., et al. (2003). International advertising in Western Europe: Should differences in uncertainty avoidance be considered when advertising in Belgium, France, The Netherlands and Spain? Journal of Business Communication, 40, 195-218.

Hoeken, H., Hornikx, J., \& Hustinx, L. (2009). Overtuigende teksten: Onderzoek en ontwerp. Bussum: Coutinho. 
Hoeken, H., Starren, M., Nickerson, C., Crijns, R., \& Brandt, C. van den (2007). Is it necessary to adapt advertising appeals for national audiences in Western Europe? Journal of Marketing Communications, 13, 19-38.

Hofstede, G. (1980). Culture's consequences: International differences in work-related values. Beverly Hills, CA: Sage.

Hofstede, G. (2001). Culture's consequences: Comparing values, behaviors, institutions, and organizations across nations $(2 \mathrm{e}$ ed.). Thousand Oaks, CA: Sage.

Hornikx, J., \& O’Keefe, D.J. (2007). Reclame in Europa: Reclame wel of niet cultureel aanpassen? Tekst[blad], $13,12-15$.

Hornikx, J., \& O’Keefe, D.J. (2009). Adapting consumer advertising appeals to cultural values: A meta-analytic review of effects on persuasiveness and ad liking. Communication Yearbook, 33, 38-71.

House, R.J., Hanges, P.J., Javidan, M., Dorfman, P.W., \& Gupta, V. (Red.) (2004). Culture, leadership, and organizations: The GLOBE study of 62 societies. Thousand Oaks, CA: Sage.

Jackson, S. (1991). Meta-analysis for primary and secondary data analysis: The super-experiment metaphor. Communication Monographs, 58, 449-462.

Mooij, M. de (2005). Global marketing and advertising: Understanding cultural paradoxes (2e ed.). Thousand Oaks, CA: Sage.

Pair, R. le, Crijns, R., \& Hoeken, H. (2000). Het belang van cultuurverschillen voor het ontwerp van persuasieve teksten. Tijdschrift voor Taalbeheersing, 22, 358-372.

Pelsmacker, P. de, Geuens, M., \& Bergh J. van den (2008). Marketingcommunicatie (3e ed.). Amsterdam: Pearson Education Benelux.

Schwartz, S. (1992). Universals in the content and structure of values: Theoretical advances and empirical tests in 20 countries. In M.P. Zanna (Red.), Advances in experimental social psychology (Vol. 25, pp. 1-65). Orlando, FL: Academic.

Shavitt, S., Lee, A.Y., \& Johnson, T.P. (2008). Cross-cultural consumer psychology. In C.P. Haugtvedt, P.M. Herr, \& F.R. Kardes (Red.), Handbook of consumer psychology (pp. 1103-1131). New York: Erlbaum.

Singelis, T.M. (1994). The measurement of independent and interdependent self-construals. Personality and Social Psychology Bulletin, 20, 580-591.

Smith, P.B., \& Schwartz, S.H. (1997). Values. In J.W. Berry, M.H. Segall, \& C. Kagitçibasi (Red.), Handbook of cross-cultural psychology:Vol. 3. Social behavior and applications (2e ed., pp. 77-118). Boston:Allyn \& Bacon.

Taylor, C.R. (2002). What is wrong with international advertising research? Journal of Advertising Research, 42 (6), 48-54.

Taylor, C.R., \& Johnson, C. (2002). Standardized vs. specialized international advertising campaigns: What we have learned from academic research in the 1990s. New Directions in International Advertising Research, 12, $45-66$.

Triandis, H.C., \& Suh, E.M. (2002). Cultural influences on personality. Annual Review of Psychology, 53, 133-160.

White, R. (2000). International advertising: How far can it fly? In J.P. Jones (Red.), International advertising: Realities and myths (pp. 29-40). Thousand Oaks, CA: Sage. 